\title{
Analysis of the COVID-19 Pandemic's Impact on the Cruise Shipping Network in the
}

\section{Asian-Australasian Region}

Author(s): Maneerat Kanrak, Hong-Oanh Nguyen, Yuquan Du

Source: Journal of International Logistics and Trade 2022; 20(1)

Published by: Jungseok Research Institute of International Logistics and Trade, Inha University

DOI: https://doi.org/10.24006/jilt.2022.e1

Journal of International Logistics and Trade is an official journal published by Jungseok Research Institute of International Logistics and Trade, Inha University, Korea. JILT welcomes manuscripts that advance the practice and science of logistics, trade, and other related fields.

Frequency: Quarterly (March, June, September, December)

Stable URL: https://www.ejilt.org

Jungseok Research Institute of International Logistics and Trade is a specialized academic research institute representing Inha University and Inha Foundation in Korea. The institute aims to become a representative institute in Northeast Asia in the research of logistics and trade.

Stable URL: https://jrieng.inha.ac.kr

(C) Copyright. Jungseok Research Institute of International Logistics and Trade.

This is an Open-Access article distributed under the terms of the Creative Commons Attribution NonCommercial License (http://creativecommons.org/licenses/by-nc/4.0/) which permits unrestricted noncommercial use, distribution, and reproduction in any medium, provided the original work is properly cited 



\title{
Analysis of the COVID-19 Pandemic's Impact on the Cruise Shipping Network in the Asian-Australasian Region
}

\author{
Maneerat Kanrak, Hong-Oanh Nguyen ${ }^{*}$, Yuquan Du
}

National Centre for Ports and Shipping, Department of Maritime and Logistics Management, Australian Maritime College, University of Tasmania, Tasmania, Australia

Received June 09, 2021
Revised $\quad$ September 11, 2021
Accepted October 18, 2021

*Corresponding author: Hong-Oanh Nguyen
National Centre for Ports and Shipping,
Department of Maritime and Logistics
Management, Australian Maritime College,
University of Tasmania, Tasmania, Australia
Tel: +61-424112119
E-mail: o.nguyen@utas.edu.au

\begin{abstract}
This study investigated the impact of the coronavirus disease 2019 (COVID-19) pandemic on the Asian-Australasian cruise shipping network. The analysis was carried out using complex network analysis and data collected for two periods, before and after the pandemic outbreak. The analysis revealed that the network structure and properties have changed after the outbreak of the COVID-19 pandemic. Interestingly, the network's density and the number of links have increased, but its scale-free property remains with the degree distribution follows the power law. The network has a higher connectivity efficiency with a smaller average path length and a higher clustering coefficient. Its hub ports still maintain an extensive connection. The network's flow efficiency becomes higher and connectivity stronger after the pandemic. The role of cruise ports has changed as indicated by the degree, betweenness, closeness and eigenvector centralities. The study's findings indicate that the cruise shipping sector could further enhance efficiency and identify strategies to assist the management in similar circumstances.
\end{abstract}

Keywords Cruise shipping network, Coronavirus, Network change, Complex network analysis, Cruise operations, Asia and Australasia

\section{Introduction}

Coronavirus disease 2019 (COVID-19) was first identified in Wuhan, China, in late 2019 and had since spread across countries around the globe. Soon after the outbreak, cruise ships became a source of infection (Kara et al. 2020; Rocklöv et al. 2020), with a large number of confirmed cases on many cruise ships. For example, the Diamond Princess had more than 700 infected people and 12 deaths, and the Ruby Princess had more than 600 infected people, with 22 associated deaths. By 13 April 2020, the virus had been found on 34 other ships with more than 1,000 confirmed cases (Cain et al. 2020; Panetta 2020). Up to now, on 12 May 2021, the virus infected more than 158 million people and caused 3,299,764 deaths worldwide, according to the World Health Organization (WHO 2021).

It was believed that evacuating passengers without proper medical measures in place could lead to more cases onshore (Rocklöv et al. 2020). Thus, passengers and crew were quarantined onboard after anchoring. Responding to the pandemic, ports and relevant authorities issued travel restrictions to all means of passenger transport. Ultimately, the Centers for Disease Control and Prevention (CDC) issued a No Sail Order, requiring US cruise lines to suspend their sailings in 2020. Cruise lines were also required to report death or illness onboard and the management details of ill passengers and crew (CDC 2020). Simultaneously, the Cruise Lines International Association (CLIA) required its members to fit medical facilities that met the standard of the American College of Emergency Physicians on their ships (CLIA 2021). In addition, many governments adopted strategies for controlling passengers from cruises entering their countries. This included refusal of entry for people from countries or ships with confirmed cases. In response, cruise lines cancelled or suspended most itineraries for the remaining period of 2020. Yet, they planned to resume sailings from 2021 and rescheduled their voyages to avoid ports in those regions with a high infection rate. For example, Carnival Cruise Line (CCL) paused operations in the USA (CCL 2020). Royal Caribbean International (RCI) redesigned its sailing itineraries in China for the first half of 2021 (RCI 2020). Norwegian Cruise Line (NCL) cancelled cruises in China and Northern Asia (Hurtibise 2020).

Although the impact of the COVID-19 pandemic on the cruise shipping sector, especially cruise passengers and shipping activities has been well covered by the news media, there is limited research on the impact on the sector especially its network. 
This study aims to address the above-mentioned gap in the literature. In particular, it aims to answer the question "how has the cruise shipping network changed as a result of the pandemic?". As shown in the next section, changes in the cruise shipping network are inevitable because of changes in market conditions, cruising operations, and business strategies as cruise lines seek to restore their services, improve traveller experience or look for new opportunities.

Section 2 reviews the responses of cruise lines to the pandemic and the resulting changes to the cruise sector. Section 3 presents a review of the literature on maritime network analysis. Section 4 explains the research methodology, and Section 5 presents the results of the analysis. Section 6 presents the managerial implications for the sector. The article concludes with implications for future research.

\section{Impacts of the pandemic on cruise shipping}

\subsection{Operational impacts}

As travel restrictions were imposed, and fear about the impact of the COVID-19 pandemic spread, the cruise sector's operations almost came to a halt. For example, CCL demonstrated hundreds of confirmed cases onboard nearly half the fleets of the cruise ships. In response to the pandemic, CCL (2020) followed travel restrictions and disease prevention policies. The cruise line denied boarding to all customers aged 70 years or above unless they had a medical certificate to prove they were fit to sail. Customers were also asked about their medical history in the past two months and their history of chronic or severe medical conditions. Travellers with such medical conditions were not allowed to board. CCL followed the social distancing policy as ships were not operating up to their full capacities (Hines 2020). CCL also increased hygiene standards by increasing sanitation, disinfection and cleaning measures. These measures included frequent sanitisation of common areas, deep cleaning and disinfection process at night, increasing the temperature in washers and dryers for enhanced disinfection of laundered goods, hand-washing sinks or hand sanitiser available at the entrance to common rooms, and surfaces and fixtures thoroughly cleaned up to twice daily. In addition, CCL distributed and updated travellers about COVID-19 and sailings through its webpage with details of ship cleaning standards, healthy cruising tips, additional tips for healthy cruising and guidelines for enhancing well-being and dealing with the situation.

Due to the continued evolution of the coronavirus, CCL suspended many of its itineraries. The cruise line offered two options to customers whose bookings were cancelled. The first option was to change the sailing dates. Customers would get the same package as their original bookings and an extra US $\$ 900$ onboard for next bookings with at least six nights, or US $\$ 450$ for cruises with fewer than six nights. The second option was to refund fully those who did not want to sail. CCL planned to resume sailing in August 2020, starting with fewer ships and fewer passengers. The operational capacity was kept at a low level for the rest of 2020. But this came at a large financial loss as the cruise line had to seek funding from the stock market to sustain its operations (Sachs et al. 2020). CCL decided to downsize the fleet by selling off 13 ships (Hines 2020). On the other hand, the company tried to attract customers by lowering the prices (Sigalos 2020).

Similar to CCL, RCI also carried out various measures to respond to the pandemic in 2020. It denied boarding to guests who had severe and chronic medical conditions. This restriction also applied to those aged 70 years or above unless they provided certification of their health condition by qualified physicians. The cruise line also took additional measures to keep guests healthy by avoiding impacted countries, enhancing boarding screening, increasing sanitation at cruise terminals and having more health safeguards onboard. RCI also had rigorous medical protocols to help unwell passengers, such as complimentary medical consultations for guests with fever or flu-like symptoms and medical isolation (RCI 2020).

RCI offered different options for passengers whose bookings were cancelled. To retain passengers, the company provided a future cruise credit with a $125 \%$ extra fare discount for next bookings. The lift and shift option was offered to passengers who wanted to move their existing bookings to 2021 sailings. A full refund option was offered to passengers who did not want to sail. In addition, passengers who purchased refundable flights or accommodations through the cruise line would automatically get a refund within 45 days after cancellation.

RCI teamed up with NCL to develop and improve safety standards called 'Healthy Sail Panel' before resuming operations amid the pandemic. The panel comprised experts in public health, biosecurity, epidemiology, hospitality and maritime operations. It provided a robust and comprehensive set of protocols and recommendations covering many possible scenarios and minimising risk. The panel was reviewed and approved by the CDC before it was adopted.

So far, the situation is that most cruise lines still suspend some itineraries and may restart depending on travel restrictions, policies and new health measures in each country (Thakkar 2021). In the first quarter of 2021, cruise lines serviced passengers 
with a small number of voyages and increased sailings to more than 2,000 voyages in the second quarter onwards (Ecruising 2021). Some voyages had been modified to better suit the situation by removing some ports and changing sailing routes.

\subsection{Economic impacts}

The suspension of cruise operations has had a significant impact on the global economy. According to CLIA (2021), in 2019, the industry contributed US\$ 154.5 billion worldwide by supporting $1,166,000$ jobs with US\$50.53 billion in wages and providing opportunities to shore-based businesses in destination regions.

RCI revealed that a suspension of its sailings in Asia decreased its earnings in 2020 by US $\$ 0.55-$ US $\$ 0.65$ per share (Telegraph 2020). Cruise lines were expected to pay refunds for cancellation and compensation fees to passengers whose cruises were cancelled. They also bore operational costs such as port fees and charges due to quarantine measurements, and maintenance and operational costs as ships were forced to remain in international waters or turned away from ports. The outbreak also resulted in a reduction of cruise lines' values on the stock market. CCL's share price dropped by nearly $60 \%$, while RCI and NCL dropped more than 70\% (AP News 2020). At the same time, their market shares plunged by an average of $35 \%$ (Wastnage 2020).

Travel demand for transport services as well as cruise shipping demand dropped substantially during the pandemic outbreak because of travel restrictions (Holland et al. 2021; Hörcher et al. 2021). However, booking demand for cruise shipping appeared to be strong after the pandemic outbreak, with the number of bookings increasing from late 2021 through 2023 (TWR 2021). Almost $60 \%$ of cruise bookings for 2021 were new bookings, while the rest of their reservations were re-bookings from passengers whose cruises were cancelled in 2020 (Buglar 2020).

\section{Network approach to the analysis of coronavirus disease 2019 (COVID-19)'s impact on cruise shipping}

As shown above, many cruise lines had to suspend their operations and sailings because of the pandemic. This has undoubtedly led to changes to the cruise shipping network. This section presents the approach adopted to evaluate the impact of the pandemic on the Asian-Australasian cruise shipping network.

Many studies on the analysis of maritime networks examined the structure and properties of the networks using graph theory, complex network analysis and social network analysis (Kanrak et al. 2019). Studies have generally focused on the analysis of topological structures and characteristics of networks such as those by Hu and Zong (2013), Guo et al. (2017), Kang and Woo (2017) and Kanrak and Nguyen (2021), Tsiotas and Polyzos (2015).

Studies on changes in maritime networks (in Table 1) mainly focused on evolution and changes in network topological structures, properties and centrality using graph theory and complex network analysis. The studies did not consider changes in the network and node impacted by external factors and situations. Only Vidya and Prabheesh (2020) analysed changes in the trade network under the COVID-19 pandemic. This study did not reflect changes at the node level. However, none of the studies found has compared the changes in networks before and after the pandemic to analyse its impacts. Hence, this study attempts to address this gap in the literature through an analysis of the changes in the cruise shipping network in terms of network structure, properties, connectivity, density and the role of nodes. The analysis makes use of a dataset of the Asian-Australasian cruise shipping network collected before and after the outbreak of the COVID-19 pandemic.

\section{Analysis method and data set}

In this study, the cruise shipping network is considered as a connected network where every pair of ports is connected directly or indirectly. Let $G(V, E)$ be the cruise shipping network, where $V$ is the set of nodes (cruise ports); $V=\left\{\mathrm{v}_{\mathrm{i}}=1,2, \ldots, n\right\}, n=$ $|V|$, and $E$ is the set of cruise routes as edges or links; $E=\left\{e_{i}=1,2, \ldots, m\right\}, m=|E|$. A network such as this can be presented by an adjacency matrix $A_{n x n}$ with element $a_{i j}=1$ when a connection exists between port $i$ and port $j$, and $a_{i j}=0$ otherwise. Two ports are defined to be neighbours if there is a link between them. Given the focus on the topology, the intensity of cruise shipping movement between ports (weight of a link) is not considered (see de Regt et al. 2019).

\subsection{Network structure measures}

Various network measures are adopted to study changes in the cruise shipping network before and after the pandemic 
Table 1. Previous studies on changes in maritime networks

\begin{tabular}{|c|c|c|c|}
\hline Authors & Research objective and domain & Research approach & Findings \\
\hline $\begin{array}{l}\text { Ducruet et al. } \\
\qquad(2010 \mathrm{a})\end{array}$ & $\begin{array}{l}\text { To analyse changes in hubs ports of } \\
\text { Northeast Asian liner networks in } 1996 \text { and } \\
2006 \text { according to the maritime traffic } \\
\text { growth. }\end{array}$ & $\begin{array}{l}\text { Network centrality } \\
\text { measures }\end{array}$ & $\begin{array}{l}\text { Although rapid traffic growth at Chinese ports, Korean } \\
\text { ports and Hong Kong remained polarised by } \\
\text { established hubs, there was a strong relation between } \\
\text { local port policies and the evolution of shipping } \\
\text { network design. }\end{array}$ \\
\hline $\begin{array}{l}\text { Ducruet et al. } \\
\qquad(2010 b)\end{array}$ & $\begin{array}{l}\text { To analyse the evolution of ports in the } \\
\text { Atlantic maritime network in 1996-2006. }\end{array}$ & $\begin{array}{l}\text { Network measures and } \\
\text { clustering methods }\end{array}$ & $\begin{array}{l}\text { Polarisation of the network by few dominant ports } \\
\text { occurred in parallel with the increased spatial } \\
\text { integration of this area by shipping lines. }\end{array}$ \\
\hline $\begin{array}{l}\text { Ducruet and } \\
\text { Notteboom } \\
\quad(2012)\end{array}$ & $\begin{array}{l}\text { To analyse changes in port hierarchies and } \\
\text { service configurations of the global liner } \\
\text { network in } 1996 \text { and } 2006 .\end{array}$ & $\begin{array}{l}\text { Graph theory and } \\
\text { complex network } \\
\text { analysis }\end{array}$ & $\begin{array}{l}\text { Topological properties remained stable, but } \\
\text { transshipment hub flows and gateway hub flows } \\
\text { slightly shifted among ports. }\end{array}$ \\
\hline $\begin{array}{l}\text { Laxe et al. } \\
\quad(2012)\end{array}$ & $\begin{array}{l}\text { To analyse changes in maritime networks } \\
\text { before and after the financial crisis between } \\
2008 \text { and } 2010 .\end{array}$ & $\begin{array}{l}\text { Graph theory, degree } \\
\text { and centrality }\end{array}$ & $\begin{array}{l}\text { Throughput for the transport network of cargo } \\
\text { container ships contracted, but there was not a } \\
\text { contraction in the main hub ports' distribution } \\
\text { capacity. }\end{array}$ \\
\hline $\begin{array}{l}\text { Xu et al. } \\
(2015)\end{array}$ & $\begin{array}{l}\text { To investigate the evolution of regional } \\
\text { inequality in the global shipping network } \\
\text { by analysing the changing positions of } \\
\text { world regions from } 2001 \text { to } 2012 \text {. }\end{array}$ & $\begin{array}{l}\text { Network centrality } \\
\text { measures }\end{array}$ & $\begin{array}{l}\text { East Asia remained a powerful trade region rather than } \\
\text { an intermediary in the network. Some new emerging } \\
\text { regions improved their positions. }\end{array}$ \\
\hline $\begin{array}{l}\text { Li et al. } \\
(2015)\end{array}$ & $\begin{array}{l}\text { To understand the dynamic changing of the } \\
\text { centrality of shipping areas in the global } \\
\text { shipping network from } 2001 \text { to } 2012 \text { due to } \\
\text { the world economy and trade changes. }\end{array}$ & $\begin{array}{c}\text { Network centrality } \\
\text { measures }\end{array}$ & $\begin{array}{l}\text { Europe was the centre of the network over the period, } \\
\text { but its central position was declining. }\end{array}$ \\
\hline $\begin{array}{l}\text { Kosowska- } \\
\text { Stamirowska } \\
\text { et al. (2016) }\end{array}$ & $\begin{array}{l}\text { To analyse changes in the topological } \\
\text { structure of the maritime trade network } \\
\text { between } 1890 \text { and } 2000 \text {. }\end{array}$ & $\begin{array}{l}\text { Complex network } \\
\text { analysis }\end{array}$ & $\begin{array}{l}\text { The network had a larger number of ports and links. } \\
\text { The network also evolved towards a hub-and-spoke } \\
\text { structure. }\end{array}$ \\
\hline $\begin{array}{l}\text { Vidya and } \\
\text { Prabheesh } \\
\text { (2020) }\end{array}$ & $\begin{array}{l}\text { To measure the trade interconnectedness } \\
\text { among countries in the global trade } \\
\text { network under the COVID- } 19 \text { outbreak and } \\
\text { forecast the future trade direction. }\end{array}$ & $\begin{array}{l}\text { Trade network } \\
\text { analysis and artificial } \\
\text { neural network }\end{array}$ & $\begin{array}{l}\text { Trade interconnectedness connectivity and density } \\
\text { among countries reduced, and the network's structure } \\
\text { changed after the pandemic outbreak. }\end{array}$ \\
\hline
\end{tabular}

COVID-19, coronavirus disease 2019.

outbreak, including network density, average path length, diameter, average clustering coefficient and degree distribution. The different measures will be further described, allowing us to conclude changes in the structure, topology and characteristics of the network.

\subsubsection{Network density}

Network density is a measure of the connectivity level of a network, which corresponds to the actual number of connections and the number of possible connections between ports in a network $G(V, E)$. It is defined as the ratio of the number of links and the maximum possible number of links in a network (Scott 1988), presented as:

$$
\rho(G)=\frac{m(G)}{n(n-1)}
$$

where $m(G)$ is the number of links, and $n$ is the total number of ports in a network. In the case of the cruise network, density is used to analyse its connectivity level.

\subsubsection{Average path length}

Average path length refers to the topological distance between all pairs of ports along the shortest paths (Watts and Strogatz 1998). This is calculated as the ratio of the sum of the shortest distance between port $i$ and port $j$ and the number of possible links: 


$$
L=\frac{1}{n(n-1)} \sum_{i \neq j}^{n} d(i, j),
$$

where $d(i, j)$ stands for the shortest distance from ports $i$ to $j$.

\subsubsection{Diameter}

Diameter measures the topological length of a network, counting the number of links in the shortest path between the two most distant ports. In other words, it is the longest geodesic distance between two ports, defined as the maximum number of links in the shortest path from ports $i$ to $j$ :

$$
\delta=\max _{i j}\{d(i, j)\}
$$

The average path length and diameter reflect the efficiency of network connectivity. A shorter average path length indicates more efficiency in network connectivity. Likewise, a shorter diameter signifies a more compact network as its nodes are more easily connected (with few steps between them) (Scardoni and Laudanna 2012).

\subsubsection{Clustering coefficient}

The clustering coefficient indicates the degree to which ports tend to cluster together. The clustering coefficient of port $i\left(C_{i}\right)$ is the ratio of the number of pairs of its neighbours connected by links $\left(E_{i}\right)$ and the maximum possible links between them:

$$
C_{i}=\frac{E_{i}}{k_{i}\left(k_{i}-1\right) / 2},
$$

where $k_{i}$ is the number of links connected to port $i$ (Watts and Strogatz 1998). Therefore, the clustering coefficient of a network is the average clustering coefficients of all ports:

$$
C=\frac{1}{n} \sum_{i=1}^{n} C_{i}
$$

This coefficient is used to analyse the intra-connectivity among ports within the cruise network, which expresses the probability of meeting cruise shipping connections among neighbours of a port. It is also used as an index of the local cruise shipping (neighbourhood) connectivity around a port (Tsiotas and Polyzos 2015).

\subsubsection{Degree distribution}

Degree distribution reflects the distribution of the links that a port shares with others. It is defined as the proportion of ports which have degree $k\left(n_{k}\right)$ and the total number of ports in the network (Barabási and Albert 1999):

$$
p(k)=\frac{n_{k}}{n} .
$$

The degree distribution is a property of the full-scale structure of a network, reflecting its characteristics and connectivity (Newman 2003). The characteristics of the cruise shipping network can be identified using average path length $(L)$, clustering coefficient $(C)$ and degree distribution $p(k)$. A random network with short $L$, small $\mathrm{C}$ and $p(k)$ is Binomial or Poisson. Smallworld, scale-free and real networks usually have a short $L$ and a large $C$. Their $p(k)$ is exponential, power-law or similar to power-law, respectively.

\subsection{Centrality measures}

The network measures mentioned above helps to reveal the overall characteristics of a network as a whole. However, they 
cannot be used to understand its nodes, which requires the use of local metrics that are specific to individual nodes. These include degree, betweenness, closeness and eigenvector centralities.

\subsubsection{Degree centrality}

Degree centrality is a basic measure reflecting the number of neighbours that directly connect to a node (port). Degree centrality of port $i$ is defined as the number of ports to which it is connected:

$$
C_{D}(i)=\sum_{j=1}^{n} a_{i j}
$$

where $a_{i j}$ is 1 if ports $i$ and $\mathrm{j}$ are connected by a link; 0 otherwise. The average degree centrality of the network reflects the average connectivity level of ports. The port with the highest degree centrality indicates it has the highest connection. It is therefore defined as an important and hub port in the network. This measure is also used to analyse the spatial structure of the network and identify its regional hubs.

\subsubsection{Betweenness centrality}

Betweenness centrality of port $i$ is the proportion of the shortest paths passing through it $\left(\sigma_{s, t}(i)\right)$ to the total number of shortest paths $\left(\sigma_{s, t}\right)$ :

$$
C_{B}(i)=\sum_{s \neq i \neq t} \frac{\sigma_{s, t}(i)}{\sigma_{s, t}} .
$$

Betweenness centrality reflects the degree to which a port can take an 'intermediary' role and its potential accessibility. It also provides information about the hub-and-spoke structure of the network; high average betweenness centrality indicates that the network does not have a strong hub-and-spoke structure.

\subsubsection{Closeness centrality}

Closeness centrality of port $i$ is the inverse of the average shortest path from it to the others in the network, calculated as:

$$
C_{C}(i)=\frac{n-1}{\sum_{j \neq i} d(i, j)} .
$$

It is easier for a port with a higher closeness centrality to reach all others in the network. In this case, closeness centrality is used to interpret the convenience for cruise ships as they sail between one port and others.

\subsubsection{Eigenvector centrality}

Eigenvector centrality considers the importance of other ports in the network. Therefore, this indicator measures the influence of a port being connected to other important ports. The eigenvector centrality of port $i$ is defined as proportional to the sum of its neighbours' centralities, written as:

$$
C_{e}(i)=\frac{1}{a} \sum_{j} g_{i j} C_{j}
$$

where $a$ is a constant, $g_{i j}$ is the adjacency matrix, and $C_{j}$ is the centrality of port $j$. A port with a higher eigenvector centrality indicates a greater influence of a port because it is connected to other important ports. It is used to analyse the development potential of a port. 


\subsection{Data set}

To study the impact of the pandemic on the cruise shipping network, the above network measures are used to compare the cruise network in Asia and Australasia before and after the pandemic outbreak. The itinerary data for cruising in 2018 and 2021 were collected from the Australian cruise shipping agent travel (https://www.ecruising.travel/). The dataset covers the network of 139 cruise ports in 20 countries in Asia and Australia and 400 total voyages over the entire year, serviced by 12 international cruise lines. Note that the dataset in 2021 was collected in 2020 during the COVID-pandemic, and any cancellations and schedule changes in itineraries were not considered and updated. This study defined ports as stops on itineraries by cruise ships, e.g. terminals, ports, beaches, islands and bays. The Asian and Australasian regions were chosen not only because they are one of the most dynamic and emerging markets but also the largest proportion of global cruise passengers (20\%) come from these two regions (Campbell 2020). Network analysis is conducted using R statistical software.

\section{Empirical findings}

\subsection{Changes in network structure}

This section presents the results of an analysis of the COVID-19's impact on the Asian-Australasian cruise shipping network. The impact is analysed as the changes to the network before and after the pandemic using cruise shipping data collected for the two years, 2018 and 2021. Figure 1 shows 471 links between ports in 2018. Figure 2 shows that the (proposed) number of links has increased 491 links for 2021, although 13 ports were not connected to others, i.e., Hamilton Island, Kuching, Lianyungang, Los Angeles, Palopo, Qingdao, San Diego, San Francisco, Sanya, Ternate, Tokushima, Yantai and Zhujiajian. A large number of links indicates that cruise lines changed and increased their sailing routes. The reason for the removal of these ports from sailings could be because cruise lines rescheduled their itineraries to avoid ports in areas with a large number of infected people and low demand for cruise shipping. In contrast, other ports benefitted from this change.

Table 2 summarises the changes in the key network measures of the Asian-Australasian cruise shipping network before and after the pandemic outbreak. These measures demonstrate significant changes in the network properties between the two periods. Overall, network density increased from 0.0246 in 2018 to 0.0256 in 2021, indicating a chance of a port connected to another or network connectivity increased from $2.46 \%$ to $2.56 \%$. It is worth noting that the 2021 sailing data represented a higher density of the network. This might be because cruise lines increased the number of routes in the network and removed ports with low connectivity.

Average path length and diameter reflect the efficiency of the cruise shipping network in terms of the convenience for cruise travellers to reach any ports in the network. Before the pandemic, the network's average path length was 5.910, higher than that in 2021, when the average was 4.666. This implies that cruise ships had a higher ability to reach ports. The shorter average path length of the network after the pandemic is due to more new links/sailings added to the network. The average number of ports per voyage of itineraries was ten ports in 2018 but nine ports in 2021. The shortest path between the two most distant ports or diameter of the network was 67 in 2018 and 27 in 2021, confirming that the network was tighter post-pandemic, with a lower diameter. After the pandemic, the relatively smaller average path length and diameter imply that cruise ships reach ports earlier with shorter distances.

Table 2. Summary of network properties

\begin{tabular}{lrrr}
\hline \multicolumn{1}{c}{$\quad$ Measure } & 2018 & 2021 & Difference \\
Ports & 139 & 139 & 0 \\
Links & 471 & 491 & 20 \\
Density & 0.0246 & 0.0256 & 0.0010 \\
Average path length & 5.91 & 4.666 & -1.244 \\
Diameter & 67 & 27 & -40 \\
Average clustering coefficient & 0.255 & 0.348 & 0.093 \\
Average degree centrality & 7.209 & 7.065 & -0.144 \\
Average betweenness centrality & 710.06 & 389.7 & -320.36 \\
Average closeness centrality & 0.19 & 0 & -0.19 \\
Average eigenvector centrality & 0.04 & 0.05 & 0.01 \\
\hline
\end{tabular}




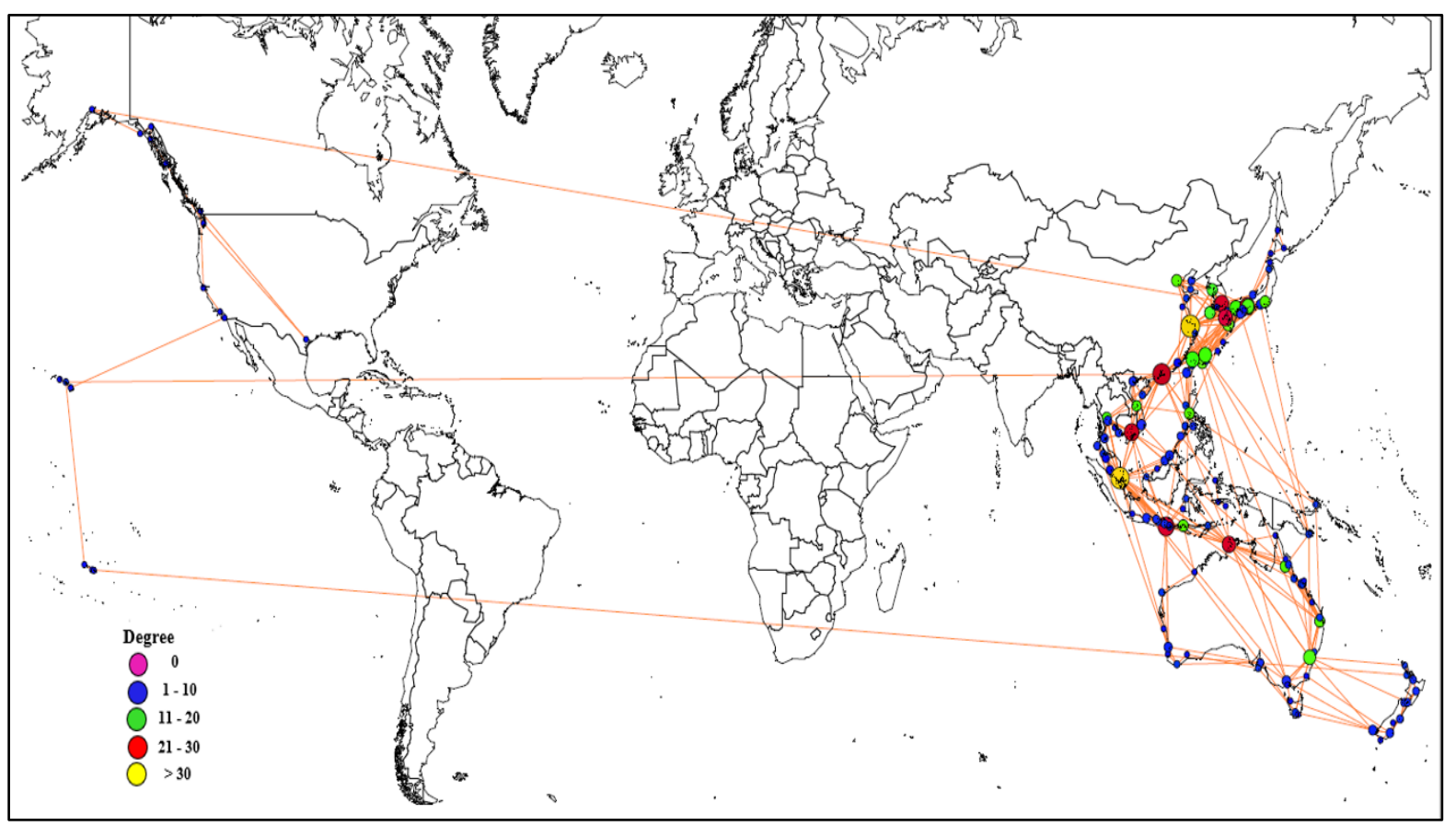

Figure 1. Cruise shipping network before the outbreak of the COVID-19 pandemic in 2018. COVID-19, coronavirus disease 2019.

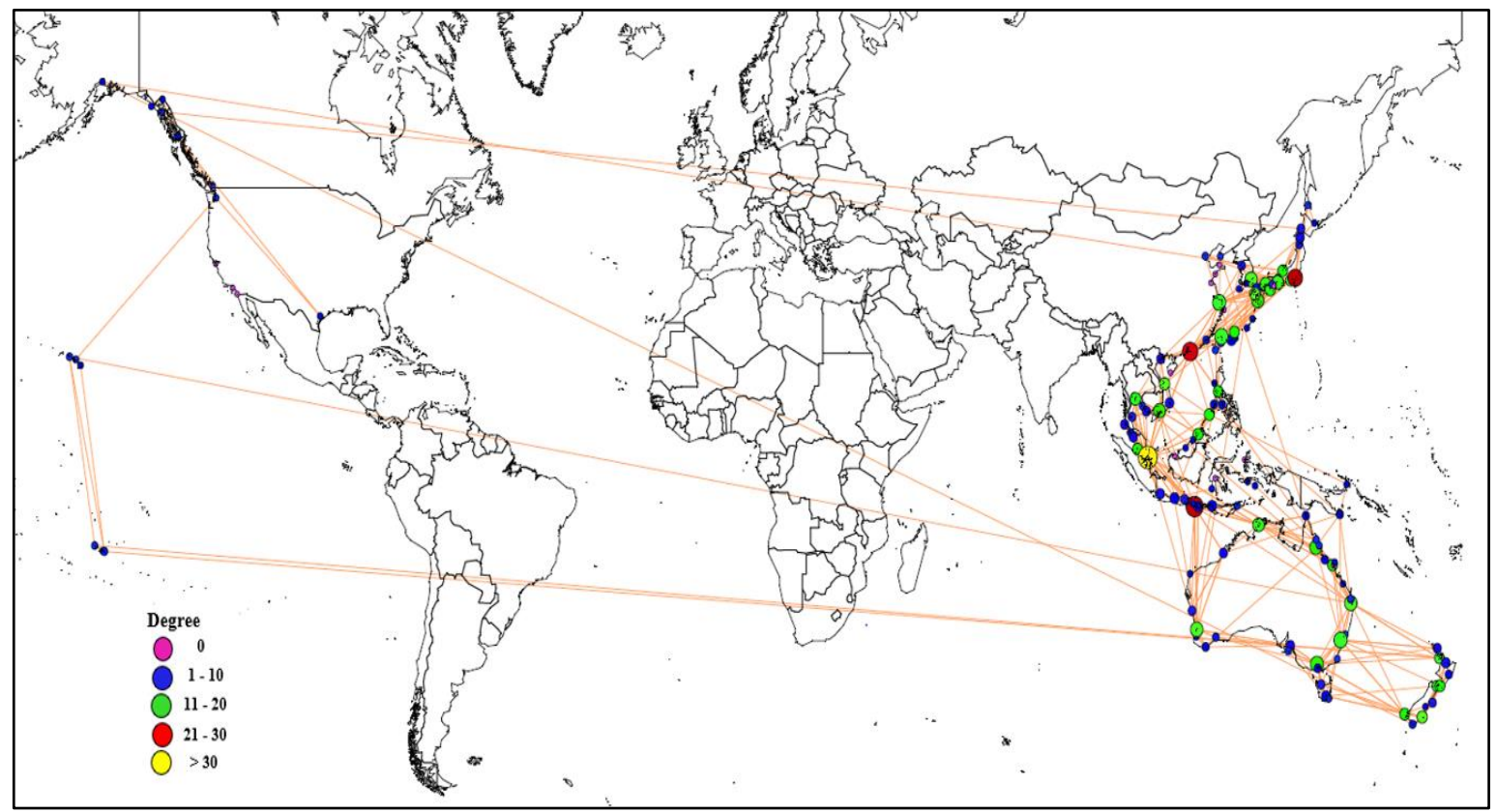

Figure 2. Cruise shipping network in 2021.

The clustering coefficient reflects the intra-connectivity among ports reflected by the probability of meeting linked neighbours of ports within the network. The network's average clustering coefficient increased from 0.255 in 2018 to 0.348 in 2021. This indicates that the probability of meeting connected neighbours around a port increased to $34.0 \%$ after the pandemic. That is, a port had stronger connectivity with its neighbours (excluding the isolated ports).

The decrease in the average degree of the cruise network from 7.209 in 2018 to 7.065 in 2021 indicates a lower connectivity level of ports after the pandemic outbreak. Ports had a lower chance of being connected to each other. The average betweenness centrality of the network substantially decreased from 710.06 in 2018 to 389.70 in 2021 . This indicates the lower accessibility of the network. The lower average betweenness centrality in 2021 also implies that the network had a stronger hub-and-spoke 

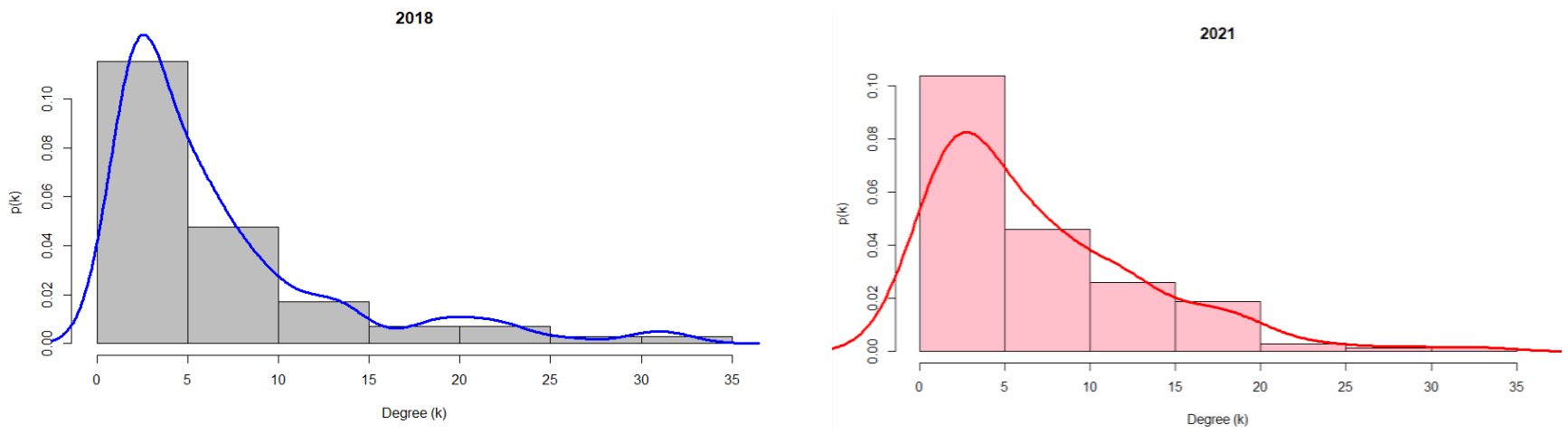

Figure 3. Degree distributions of cruise ports in 2018 and 2021.

structure.

The decrease in the network's average closeness centrality from 0.19 to 0.00 over the period indicates the network's connectivity has become more decentralised. However, the average eigenvector centrality of the network increased from 0.04 in 2018 to 0.05 in 2021, indicating the tendency for ports to connect to influential ports.

Figure 3 shows degree distributions that reflect how the connections are distributed among possible pairs of ports. As demonstrated by the graphs, degree distributions of the network of the two periods followed the power law. Most ports had a low connectivity level because of the small number of ports connected to them. In contrast, a few important ports had a large number of connections to others in the network. These indicate that the network had a scale-free property before and after the pandemic. It is worth noting that, while the network structure changed with a larger number of links in 2021, its degree distribution remained largely the same as in 2018. However, in 2021, ports with degrees between 10 and 20 were accounted for a higher proportion than those in 2018.

\subsection{Change in the ports' role}

Degree centrality reflects the port's importance in terms of its connectivity within the network or as a hub port. As will be shown below Singapore, Shanghai, Hong Kong, Benoa, Ho Chi Minh and Kobe were the most important ports in 2018. Each played a hub role dominating connections in the network. However, in 2021, Yokohama, Keelung and Sydney became new hub ports replacing Ho Chi Minh and Kobe. Singapore was ranked top, with the highest degree centrality before and after the pandemic outbreak, indicating that it remains the most influential port in the network. Before the pandemic, the network had 64 ports with degree 2 , while 31 ports had degrees 1 and 2 after the pandemic. This is the result of the heavy reliance of cruise lines on hub ports for health safety reasons.

In terms of the spatial distribution of degree centrality, ports with a high connectivity level were in fewer countries after the pandemic because itineraries were rescheduled to avoid visiting regions with many infected cases. Singapore, Indonesia, Japan, Hong Kong and China were the cruise shipping hubs across both periods, reflecting the fact that these countries were popular for cruise shipping both pre-and post-pandemic. Vietnam's role as a hub was diminished, while Taiwan and Australia became more important countries post-pandemic. In 2018, a few ports had more than 30 degrees and seven ports with 21-30 degrees (Figure 1). In 2021, only one port had a degree higher than 30, and a few ports had degrees between 21-30 (Figure 2). Most

Table 3. Betweenness centrality distributions of cruise ports in 2018 and 2021

\begin{tabular}{|c|c|c|c|c|}
\hline \multirow{2}{*}{ Betweenness } & \multicolumn{2}{|c|}{2018} & \multicolumn{2}{|c|}{2021} \\
\hline & Number of ports & Share of total $(\%)$ & Number of ports & Share of total $(\%)$ \\
\hline 0 & 18 & 12.95 & 29 & 20.86 \\
\hline $1-500$ & 70 & 50.36 & 77 & 55.40 \\
\hline $501-1,000$ & 17 & 12.23 & 18 & 12.95 \\
\hline $1,001-1,500$ & 4 & 2.88 & 6 & 4.32 \\
\hline $1,501-2,000$ & 15 & 10.79 & 3 & 2.16 \\
\hline$>2,000$ & 15 & 10.79 & 6 & 4.32 \\
\hline
\end{tabular}


ports with 1-10 degrees were located across many countries in the Asian-Australasian region in both periods.

Regarding the betweenness centrality of ports, Hong Kong had the highest betweenness centrality in 2018 , followed by Sydney, Melbourne, Shanghai and Singapore. In 2021, Benoa became the port with the highest betweenness centrality, followed by Hong Kong, Brisbane, Singapore and Fremantle, while Sydney, Melbourne and Shanghai were no longer the top five hubs in 2021. This indicates that some ports with high accessibility were replaced by others after the pandemic since cruise lines wanted to change intermediary ports between pairs of other cruise ports which are not directly connected for cruise shipping. Table 3 shows the betweenness centrality distributions of cruise ports in the cruise shipping network. In 2018, most ports had betweenness centrality lower than 1,000, while few possessed values higher than 5,000. Likewise, in 2021, most ports had betweenness centrality lower than 1,000. Before the pandemic, $12.95 \%$ of ports were peripheral ports with a betweenness centrality of zero (i.e., they had no shortest path between them and another port). However, in 2021 this increased to 20.86\%, confirming a stronger hub-and-structure of the network.

In both periods, Indonesia, Hong Kong, Australia and Singapore had ports with the highest betweenness centrality. In 2018, many ports had the betweenness centrality higher than 2000. These were Hong Kong, Australia, China, Singapore, Indonesia, New Zealand, French Polynesia, USA, Vietnam and Japan, as shown in Figure 4a. This situation was not the case in 2021 when only six ports in Indonesia, Hong Kong, Australia, Singapore and South Korea had betweenness centrality values higher than 2000, as illustrated in Figure 4b. This result indicates that fewer counties were able to maintain their central role in the network

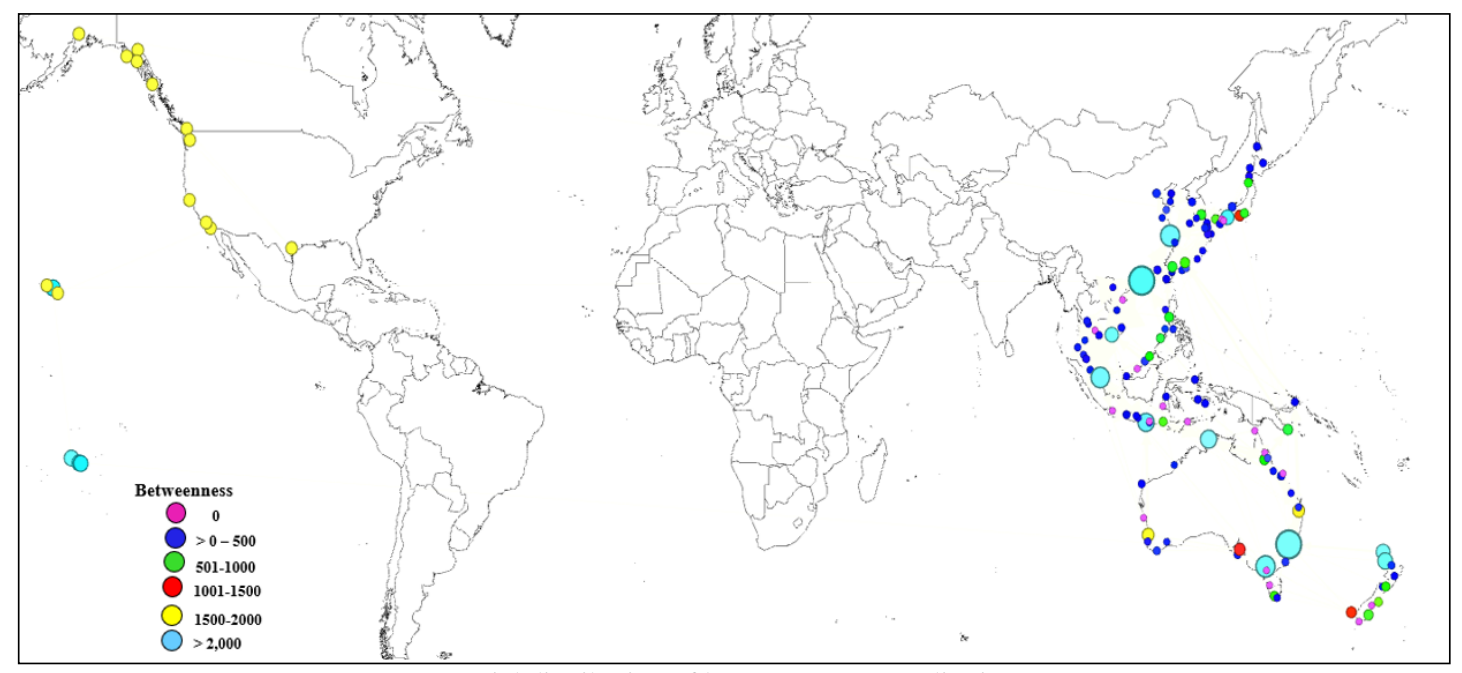

(a) Spatial distribution of betweenness centrality in 2018

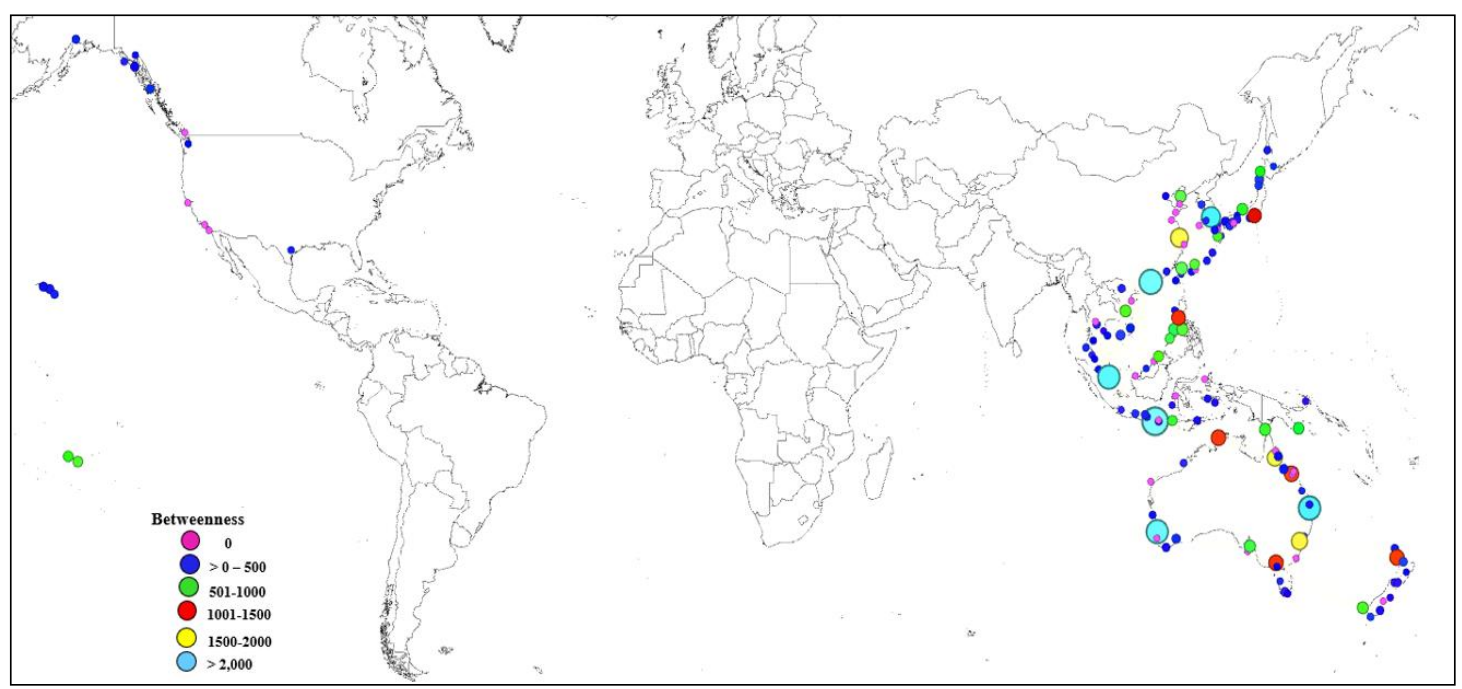

(b) Spatial distribution of betweenness centrality in 2021

Figure 4. Spatial distributions of betweenness centrality of cruise ports. 
after the pandemic outbreak. This trend is a good representation of the globalisation process of cruise shipping. Changes in betweenness centrality values follow a similar geographic pattern with more drastic gaps among ports. This clearly shows the strong effects of hub strategies at the six ports and the emergence of load centres in Indonesia, Hong Kong, Australia, Singapore and South Korea in 2021. This indicates the emergence of economics and differentiation of ports after the pandemic according to local and global changes in cruise routes and port selection.

Regarding the ports' closeness centrality, closeness centrality distributions of the network for two periods of interest are shown in Figure 5. As illustrated by the graph, in 2018, most ports had the closeness centrality between $0.16-0.25$ accounted for $79.14 \%$ of ports, and there were no ports that had the closeness centrality value of zero. In 2021, all ports had the closeness centrality of zero, indicating that ports were not connected to all other ports in the network after the pandemic. Before the pandemic, Melbourne had the highest closeness centrality, followed by Hong Kong, Shanghai, Sydney, Brisbane and Shimizu, reflecting that they had the highest reachability to all other ports in the network. However, the ports no longer reached all other ports in 2021, reflected by their closeness centrality value of zero.

Eigenvector centrality represents the influence of a port in the network in terms of other influential ports connected to it. Therefore, this measure can be used as an indicator of its development potential. Table 4 shows that 68 ports in 2018 had the eigenvector centrality value of zero, which decreased to 35 ports in 2021 . Additionally, ports with eigenvector centrality between $0.01-0.20$ in 2021 were accounted for higher proportions than those in 2018. In contrast, in 2021, ports with an eigenvector centrality of over 20 were accounted for a lower proportion compared to 2018 . These indicate that ports became more influential by being connected to other important ports. To this end, cruise ports evolved toward being the development potential ports after the pandemic. Moreover, the most development potential ports with the highest eigenvector centrality in 2018 were replaced by others in 2021. Shanghai, Keelung, Nagasaki, Busan and Kobe were ports with development potential in 2018. However, development potential ports in 2021 were Hong Kong, Keelung, Kobe, Kochi and Osaka, as shown in Table 5.

To sum up, the structure and properties of the Asian-Australasian cruise shipping network changed as a result of the pandemic's impact. The network had higher connectivity with a larger number of links and was more efficient. It also had a stronger hub-and-spoke structure compared to the network before the pandemic. The roles of ports were also changed to respond to the pandemic and comply with cruise lines' operations. Before the pandemic outbreak, Shanghai was the most important port in the network, with the highest values of all centrality measures. However, it only played a hub role with the highest degree in 2021. Hong Kong and Singapore still played the role of hubs and intermediary ports. Likewise, Brisbane remained a transition port in the south with high accessibility. In 2021, there were not ports with high reachability that had close relationships with all ports in the network. Benoa became a more important port. The roles of Kobe, Sydney and Ho Chi Minh were diminished, while that of Fremantle, Keelung, Kochi and Osaka were improved.

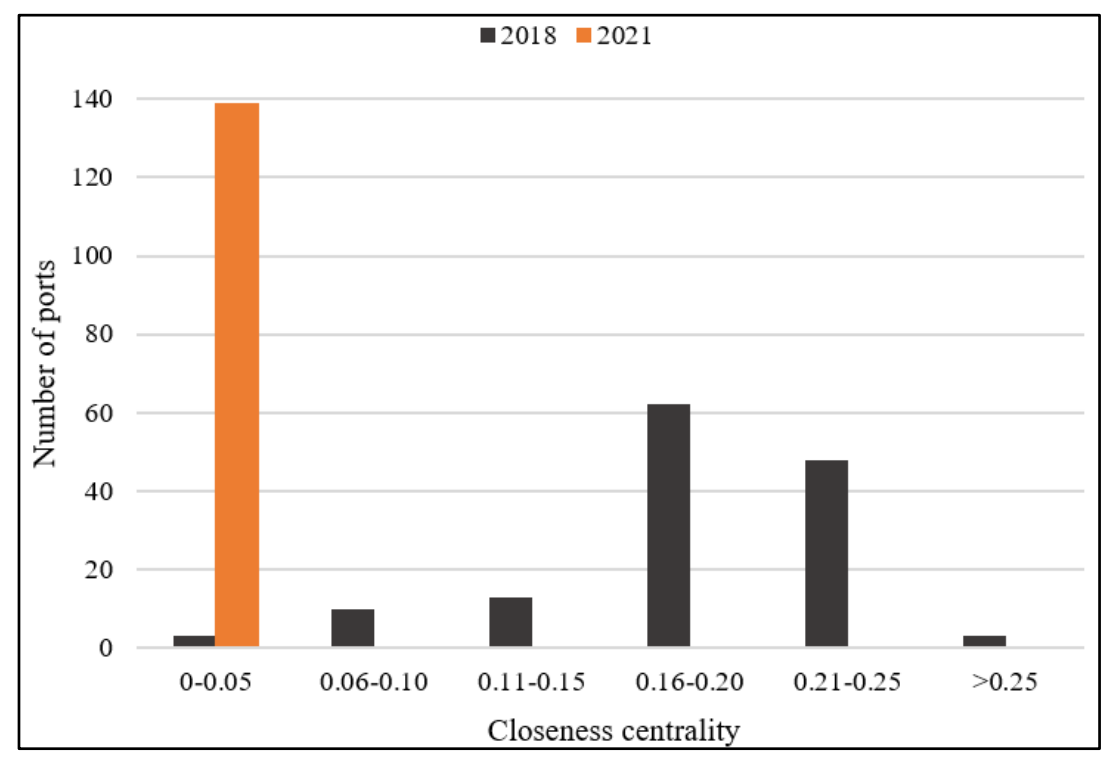

Figure 5. Closeness centrality distributions of cruise ports in 2018 and 2021. 
Table 4. Eigenvector centrality distributions of the network in 2018 and 2021

\begin{tabular}{|c|c|c|c|c|}
\hline \multirow{2}{*}{ Eigenvector } & \multicolumn{2}{|c|}{2018} & \multicolumn{2}{|c|}{2021} \\
\hline & Number of ports & Share of total $(\%)$ & Number of ports & Share of total $(\%)$ \\
\hline 0 & 68 & 48.92 & 35 & 25.18 \\
\hline $0.01-0.05$ & 44 & 31.65 & 61 & 43.88 \\
\hline $0.06-0.10$ & 10 & 7.19 & 22 & 15.83 \\
\hline $0.11-0.15$ & 3 & 2.16 & 6 & 4.32 \\
\hline $0.16-0.20$ & 5 & 3.60 & 9 & 6.47 \\
\hline $0.21-0.25$ & 5 & 3.60 & 4 & 2.88 \\
\hline$>0.25$ & 4 & 2.88 & 2 & 1.44 \\
\hline
\end{tabular}

Table 5. Most influential ports in the Asian-Australasian cruise shipping network

\begin{tabular}{|c|c|c|c|c|}
\hline \multirow{2}{*}{ Rank } & \multicolumn{2}{|c|}{ Degree centrality } & \multicolumn{2}{|c|}{ Betweenness centrality } \\
\hline & 2018 & 2021 & 2018 & 2021 \\
\hline 1 & Singapore & Singapore & Hong Kong & Benoa \\
\hline 2 & Shanghai & Benoa & Sydney & Hong Kong \\
\hline 3 & Hong Kong & Hong Kong & Melbourne & Brisbane \\
\hline 4 & Benoa & Yokohama & Shanghai & Singapore \\
\hline 5 & Ho Chi Minh, Kobe & Keelung, Shanghai, Sydney & Singapore & Fremantle \\
\hline \multirow{2}{*}{ Rank } & \multicolumn{2}{|c|}{ Closeness centrality } & \multicolumn{2}{|c|}{ Eigenvector centrality } \\
\hline & 2018 & 2021 & 2018 & 2021 \\
\hline 1 & Melbourne & - & Shanghai & Hong Kong \\
\hline 2 & Hong Kong & - & Nagasaki & Keelung \\
\hline 3 & Shanghai & - & Keelung & Kobe \\
\hline 4 & Sydney & - & Busan & Kochi \\
\hline 5 & Brisbane, Shimizu & - & Kobe & Osaka \\
\hline
\end{tabular}

\subsection{Changes in cruise operations}

The findings mentioned above reflect that cruise lines have changed their operations to respond to the pandemic. Cruise lines increased sailing routes to accommodate the growing demand after the pandemic, leading to the cruise network had a larger number of links. Cruise lines rescheduled itineraries to remove unpopular ports in areas with a high infection rate, while they increased sailings to regions with lower infection rates. Cruise lines also designed shorter itineraries consisting of ports mostly in the same areas to avoid bringing the virus across locations and increase the confidence of passengers being safe for their cruising.

Cruise lines tried to find new popular ports with a lower infection rate. At the same time, they removed some sailing routes that visit the hub ports with a high infection rate. This has led to lower connectivity of those ports. For example, cruise lines removed some sailing routes and added some to Singapore, as shown in Table 6.

In itinerary design, cruise lines considered the infection rate as one of the other factors for a cruise port selection. For instance, cruise lines designed itineraries that consists of ports in areas with no or low infection rates.

To provide the service during the COVID-19 pandemic, cruise lines had to sail with less than $70 \%$ of a ship's capacity and service shorter itineraries with fewer ports of call. Additionally, they tried to set new popular destinations for cruise shipping by designing new cruise routes that have not been in itineraries to visit the target destinations. For example, in 2021, Hong Kong was designed to connected ports that had not been connected in 2018, as shown in the following:

- Hong Kong - Busan (South Korea),

- Hong Kong - Fukuoka (Japan),

- Hong Kong - Hualien (Taiwan),

- Hong Kong - Kobe (Japan), 
Table 6. Cruise routes were removed and added to itineraries to visit Singapore in 2021

\begin{tabular}{ll}
\multicolumn{1}{c}{ Removed routes } & \multicolumn{1}{c}{ Added routes } \\
Adelaide - Singapore & Langkawi - Singapore \\
Brisbane - Singapore & Puerto Princesa - Singapore \\
Celukan Bawang - Singapore & Sihanoukville - Singapore \\
Kuching - Singapore & Surabaya - Singapore \\
Melbourne - Singapore & Da Nang - Singapore \\
Probolinggo - Singapore & Ko Kood - Singapore \\
Bandar Seri Begawan - Singapore & \\
Lembar - Singapore & \\
\hline
\end{tabular}

- Hong Kong - Okinawa (Japan),

- Hong Kong - Ishigaki (Japan),

- Hong Kong - Kochi (Japan),

- Hong Kong - Puerto Princesa (Philippines).

Some ports had much more connections than in 2018 since cruise lines designed itineraries to avoid ports in areas with high infection rates by increasing cruise routes to ports with lower infection rates and famous for cruising. Table 7 shows 27 and 23

Table 7. Ports with the number of links increased and decreased by more than $50 \%$

\begin{tabular}{|c|c|c|c|c|c|c|c|}
\hline Port & 2018 & 2021 & Increase $(\%)$ & Port & 2018 & 2021 & Decrease $(\%)$ \\
\hline Hakodate & 2 & 9 & 350 & Hamilton Island & 5 & 0 & 100 \\
\hline Tanjung Priok & 2 & 9 & 350 & Kuching & 3 & 0 & 100 \\
\hline Broome & 2 & 8 & 300 & Lianyungang & 2 & 0 & 100 \\
\hline Burnie & 2 & 7 & 250 & Los Angeles & 2 & 0 & 100 \\
\hline Geraldton & 2 & 7 & 250 & Palopo & 3 & 0 & 100 \\
\hline Otaru & 2 & 7 & 250 & Qingdao & 7 & 0 & 100 \\
\hline Phillip Island & 2 & 6 & 200 & San Diego & 2 & 0 & 100 \\
\hline Thursday Island & 2 & 6 & 200 & San Francisco & 2 & 0 & 100 \\
\hline Auckland & 4 & 11 & 175 & Sanya & 5 & 0 & 100 \\
\hline Bay of Islands & 3 & 8 & 166.67 & Ternate & 2 & 0 & 100 \\
\hline Esperance & 2 & 5 & 150 & Tokushima & 2 & 0 & 100 \\
\hline Ketchikan & 2 & 5 & 150 & Yantai & 4 & 0 & 100 \\
\hline Oban & 2 & 5 & 150 & Zhujiajian & 3 & 0 & 100 \\
\hline Tahiti & 2 & 5 & 150 & Jeju Island & 14 & 2 & 85.71 \\
\hline Bora Bora & 2 & 4 & 100 & Klong Toey & 11 & 2 & 81.82 \\
\hline Cooktown & 2 & 4 & 100 & Bandar Seri Begawan & 8 & 2 & 75.00 \\
\hline Fremantle & 9 & 18 & 100 & Probolinggo & 7 & 2 & 71.43 \\
\hline Hobart & 5 & 10 & 100 & Tianjin & 13 & 4 & 69.23 \\
\hline Honolulu & 2 & 4 & 100 & Celukan Bawang & 6 & 2 & 66.67 \\
\hline Kanazawa & 6 & 12 & 100 & Rabaul & 6 & 2 & 66.67 \\
\hline Ko Kood & 2 & 4 & 100 & Port Douglas & 8 & 3 & 62.50 \\
\hline Wellington & 6 & 12 & 100 & Kaohsiung & 9 & 4 & 55.56 \\
\hline Melbourne & 10 & 19 & 90 & Nha Trang & 19 & 9 & 52.63 \\
\hline Yokohama & 13 & 23 & 76.92 & & & & \\
\hline Laem Chabang & 8 & 14 & 75 & & & & \\
\hline Dunedin & 8 & 13 & 62.50 & & & & \\
\hline Lembar & 5 & 8 & 60 & & & & \\
\hline
\end{tabular}


ports with the number of cruise routes increased and decreased by more than $50 \%$ in 2021 . Cruise lines added seven cruise routes to Hakodate and Tanjung Priok, leading to the ports had the number of connections increased by 350\% from 2018. Likewise, six cruise routes were added to Broome. Interestingly, cruise lines increased the number of routes to ports where were not the hubs of the cruise network. This situation implies that cruise lines wanted to create new hub ports for cruise shipping. Besides 13 ports removed from itineraries, cruise lines significantly reduced the number of cruise routes to Jeju Island, Klong Toey, Bandar Seri Begawan, Probolinggo, Tianjin, Celukan Bawang, Rabaul, Port Douglas, Kaohsiung and Nha Trang.

\section{Managerial implications}

The above findings indicate that the cruise shipping network and operations have changed as a result of the COVID-19 pandemic. The findings can be used to help cruise lines and authorities improve their operations, ports and service network post-pandemic. The increased number of links from 471 to 491 in the cruise network helps cruise lines have more cruise routes to service passengers. After the pandemic, cruise lines may use the increased links as cruise routes to design attractive and safe itineraries. The efficiency of the network connectivity with a smaller average path length and diameter, and a larger clustering coefficient imply cruise passengers' preference to sail with short itineraries after the pandemic. Thus, cruise lines should service short itineraries more often than long ones. Cruise lines can even design sailings to nowhere for local vaccinated guests to minimise the infection risk, making passengers feel more confident and safer for their cruising. This strategy could attract more passengers to sail.

Many regional hubs have been changed after the pandemic. The number of regional hubs has decreased from 8 to 4 regional hubs with 20 degrees and above. This is because cruise lines focused on new regional hubs or destinations with fewer confirmed cases. Cruise lines may increase the service frequency of sailing via these hubs. This strategy benefit cruise lines in terms of having new hubs for cruise shipping. Authorities can use the new hubs to build new focal economic regions for cruising and tourism.

Given the changes to the roles and importance of ports in the cruise network, such as Shanghai, Kobe, Sydney and Ho Chi Minh were diminished their roles. Benoa, Fremantle, Keelung, Kochi and Osaka were more important ports after the pandemic since these ports had a lower infection rate. Cruise lines may need to redesign or update their sailing plan based on the infection rate information. Cruise lines may benefit more from ports with lower infection risk. The findings also help authorities promote their ports as hubs and economic focal points for cruise shipping by increasing ports' connections.

Cruise ships may not enter ports in the current network easily due to travel restrictions. Therefore, cruise lines may extend the current network by finding new destinations with low/no infection and travel restrictions for entering the areas, such as isolated islands or places with no habitants. This may be easy for cruise lines to manage their operations amid and after the pandemic. Whichever the case, cruise lines will also have to consider the overall trends in the market demand, travellers' expectations and the effects of the pandemic on cruise operations, some of which may be long term. Until the vaccine against the virus has been widely and effectively used, they need to maintain strict measures to prevent disease transmission and get ready for the market's return. Cruise lines may also have to consider the national context in terms of different countries with different infection rates and strategies to manage the pandemic (Chowdhury et al. 2021).

\section{Conclusion}

This study aimed to analyse the impact of the COVID-19 pandemic on the cruise shipping network. A complex network analysis was performed using various network statistics and data collected before and after the pandemic outbreak. It was found that the network connectivity had changed, with a larger number of links in 2021 than in 2018, influenced by suspended sailings during the period of the disease outbreak. The more significant number of links, among other factors, has led to the increased density of connections from $2.46 \%$ to $2.56 \%$, implying the network was denser in 2021 than before the outbreak.

Network efficiency increased with a smaller average path length and diameter, indicating cruise ships reached ports more easily. A higher clustering coefficient confirmed changes in the cruise shipping network post the outbreak, implying a higher connection between neighbours of a port. Although the network's structure and properties changed, it still possessed the characteristics of a scale-free network with degree distribution following the power law. This indicates that the network postpandemic still consisted of a few ports dominating the network with high connectivity and many ports with low connectivity.

The roles of some key ports changed after the pandemic. Shanghai was the most important port with high values of all centrality measures before the pandemic, but its role was diminished significantly post-pandemic. On the other hand, Singapore, 
Benoa, Hong Kong, Yokohama, Keelung and Sydney took more important roles as hub ports with a high degree centrality in 2021 sailings. An intermediary role was played by Benoa, Hong Kong, Brisbane, Singapore, and Fremantle, reflected by high betweenness centrality. All ports had no reachability to all other ports, indicated by the closeness centrality value of zero. Hong Kong, Keelung, Kobe, Kochi and Osaka were the development potential ports with a high ability to access important ports.

The findings from the above analysis are helpful for cruise lines and authorities to manage and plan their operations postpandemic. Cruise lines may increase service frequency for sailing or even expand ships' capacity via new regional hubs with high economic potential. Cruise lines may also extend the network and look for new potential destinations with a lower risk of infection to satisfy the travellers' expectations in the new normal in cruising. Authorities can use the findings to promote their destinations as hubs of cruise shipping after the pandemic by increasing ports' connections to other ports or even promote their ports to be transition ports in the network.

This study has contributed to the literature in three ways. First, it is the first study to evaluate the impact of the COVID-19 pandemic on the cruise shipping network. Second, it conducted a complex network analysis to analyse the impact of the pandemic on the network. Third, the study made use of the data of the network before and after the pandemic outbreak.

The study is also subject to limitations. The main limitation of this research is that the intensity of cruise shipping movements among ports or weights of links were not considered. Therefore, further research is needed to reveal the impact of the pandemic on the dense connection between ports in the network to help cruise lines strategise their sailings in a similar situation. Additionally, this study did not consider the seasonal effect of cruise demand and the preference of cruise travellers. Thus, future research may consider these determinants that may influence changes in the network after the pandemic.

\section{References}

AP News, 2020. Impact of COVID-19 on the Global Cruise industry: Compare key industry players' actions - Research AndMarkets.com. Associated Press News. Available at: https://apnews.com/press-release/business-wire/7f4a34 ac40734 $5 \mathrm{e} 090 \mathrm{c} 408 \mathrm{bcbb} 89 \mathrm{afda}$

Barabási, A. L., Albert, R. 1999. Emergence of scaling in random networks. Science 286, 509-512.

Buglar, E. 2020. Cruise bookings still in demand as overseas travel to and from Australia falls. Comparethemarket. Available at: https://www.comparethemarket.com.au/news/cruise-bookings-still-in-de

Cain, Á., Matousek, M., Su, R. 2020. All the cruise ships that have had confirmed cases of COVID-19 onboard. Available at: https://www.businessinsider.com/cruise-ships-with-confirmed-covid-19-cases-during-coronavirus-pandemic-2020-4?r=A $\mathrm{U} \& \mathrm{IR}=\mathrm{T}$

Campbell, A. 2020. Australian cruise industry statistics. Cruise agency. Available at: https://www.cruiseagency.com.au/news/ australian-cruise-industry-statistics/

CCL [Carnival Cruise Line]. 2020. Health and sailing update. Available at: https://www.carnival.com/health-and-sailingupdates

CDC [Centers for Disease Control and Prevention]. 2020. Travel industry resources. Available at: https://wwwnc.cdc. gov/travel/page/travel-industry-information-center

Chowdhury, P., Paul, S. K., Kaisar, S., Moktadir, M. A. 2021. COVID-19 pandemic related supply chain studies: A systematic review. Transportation Research Part E: Logistics and Transportation Review 148, 102271.

CLIA [Cruise Lines International Association]. 2021. State of the cruise industry outlook. Available at: https://cruising. org/en/news-and-research/research/2020/december/state-of-the-cruise-industry-outlook-2021

de Regt, R., von Ferber, C., Holovatch, Y., Lebovka, M. 2019. Public transportation in Great Britain viewed as a complex network. Transportmetrica A: Transport Science 15, 722-748.

Ducruet, C., Lee, S. W., Ng, A. K. Y. 2010a. Centrality and vulnerability in liner shipping networks: Revisiting the northeast Asian port hierarchy. Maritime Policy \& Management 37, 17-36.

Ducruet, C., Notteboom, T. 2012. The worldwide maritime network of container shipping: Spatial structure and regional dynamics. Global Networks 12, 395-423.

Ducruet, C., Rozenblat, C., Zaidi, F. 2010b. Ports in multi-level maritime networks: Evidence from the Atlantic (1996-2006). Journal of Transport Geography 18, 508-518.

Ecruising. 2021. Choose your cruise with great cruising destinations. E: Ecruising - cruise holiday specialists. Available at: https://www.ecruising.travel

Guo, J., Wang, S., Wang, D., Liu, T. 2017. Spatial structural pattern and vulnerability of China-Japan-Korea shipping network. 
Chinese Geographical Science 27, 697-708.

Hines, M. 2020. Carnival cruise lines plan 'staggered' comeback, won't return to full capacity until 2022. Available at: https://www.usatoday.com/story/travel/cruises/2020/07/10/carnival-corp-cruises-operations-capacity-coronavirus-2022/5 405777002/

Holland, J., Mazzarol, T., Soutar, G. N., Tapsall, S., Elliott, W. A. 2021. Cruising through a pandemic: The impact of COVID19 on intentions to cruise. Transportation Research Interdisciplinary Perspectives 9, 100328.

Hörcher, D., Singh, R., Graham, D. J. 2021. Social distancing in public transport: Mobilising new technologies for demand management under the COVID-19 crisis. Transportation. Available at: https://doi.org/10.1007/s11116-021-10192-6

Hu, B., Zong, G. 2013. Topology analysis of China's port shipping network. Journal of Software 8, 2581-2586.

Hurtibise, R. 2020. Norwegian cruise line cancels Asia voyage in response to coronavirus. Available at: https://www.sunsentinel.com/business/fl-bz-coronavirus-spawns-dilemma-for-planned-asia-cruisers-20200213-oh4medemiva2hjsn74hom cr4vq-story.html

Kang, D. J., Woo, S. H. 2017. Liner shipping networks, port characteristics and the impact on port performance. Maritime Economics \& Logistics 19, 274-295.

Kanrak, M., Nguyen, H. O. 2021. Structure, characteristics and connectivity analysis of the Asian-Australasian cruise shipping network. Maritime Policy \& Management. Available at: https://doi.org/10.1080/03088839.2021.1914876

Kanrak, M., Nguyen, H. O., Du, Y. 2019. Maritime transport network analysis: A critical review of analytical methods and applications. Journal of International Logistics and Trade 17, 113-122.

Kara, T., Stefanie B, W., Krista, K. D. 2020. Chapter 8: Cruise ship travel. CDC Yellow Book 2020. Available at: https:// wwwnc.cdc.gov/travel/yellowbook/2020/travel-by-air-land-sea/cruise-ship-travel

Kosowska-Stamirowska, Z., Ducruet, C., Rai, N. 2016. Evolving structure of the maritime trade network: Evidence from the Lloyd's shipping index (1890-2000). Journal of Shipping and Trade 1, 10.

Laxe, F. G., Seoane, M. J. F., Montes, C. P. 2012. Maritime degree, centrality and vulnerability: Port hierarchies and emerging areas in containerized transport (2008-2010). Journal of Transport Geography 24, 33-44.

Li, Z., Xu, M., Shi, Y. 2015. Centrality in global shipping network basing on worldwide shipping areas. GeoJournal 80, 47-60.

Newman, M. E. J. 2003. The structure and function of complex networks. SIAM Review 45, 167-256.

Panetta, G. 2020. Cruise ship bookings for 2021 are already on the rise despite multiple COVID-19 outbreaks. Business Insider Australia. Available at: https://www.businessinsider.com.au/cruise-ship-bookings-are-increasing-for-2021-despite-coronavirus2020-4? $\mathrm{r}=\mathrm{US} \& \mathrm{IR}=\mathrm{T}$

RCI [Royal Caribbean International]. 2020. Health and travel alerts. Available at: https://www.royalcaribbean.com/cruiseships/itinerary-updates

Rocklöv, J., Sjödin, H., Wilder-Smith, A. 2020. COVID-19 outbreak on the Diamond Princess cruise ship: Estimating the epidemic potential and effectiveness of public health countermeasures. Journal of Travel Medicine 27, taaa030.

Sachs, G., Morgan, J. P., Securities, B. 2020. Common stock - Prospectus supplement rule. Carnival Corporation. Available at: https://www.sec.gov/Archives/edgar/data/815097/000119312520092049/d897344d424b5.htm

Scardoni, G., Laudanna, C. 2012. Centralities based analysis of complex networks. In: Zhang, Y. (Ed), New Frontiers in Graph Theory. InTech Open, London, UK.

Scott, J. 1988. Social network analysis. Sociology 22, 109-127.

Sigalos, M. 2020. Carnival's struggle to survive the coronavirus as outbreak wipes out the cruise industry. CNBC. Available at: https://www.cnbc.com/2020/04/05/carnivals-struggle-to-survive-the-coronavirus-as-outbreak-wipes-out-the-cruise-indust ry.html

Telegraph. 2020. Carnival warns of coronavirus hit to earnings guidance. Available at: https://www.telegraph.co.uk/marketshub/share/S1279/CCL/Carnival

Thakkar, E. 2021. When will each cruise line resume sailings again? (2021). Cruise Hive. Available at: https://www. cruisehive.com/when-will-each-cruise-line-resume-sailings-again/39187

Tsiotas, D., Polyzos, S. 2015. Analyzing the maritime transportation system in Greece: A complex network approach. Networks and Spatial Economics 15, 981-1010.

TWR. 2021. Trade bullish about future cruise sales. Travel Weekly Reporters. Available at: https://www.travelweekly. co.uk/articles/399033/trade-bullish-about-future-cruise-sales

Vidya, C. T., Prabheesh, K. P. 2020. Implications of COVID-19 pandemic on the global trade networks. Emerging Markets Finance and Trade 56, 2408-2421. 
Wastnage, J. 2020. Will cruise lines survive COVID-19? United States Studies Centre. Available at: https://www.ussc. edu.au/analysis/will-cruise-lines-survive-covid-191

Watts, D. J., Strogatz, S. H. 1998. Collective dynamics of 'small-world' networks. Nature 393, 440-442.

WHO [World Health Organization]. 2021. Coronavirus disease (COVID-19) pandemic. Available at: https://www.who.int/ emergencies/diseases/novel-coronavirus-2019

Xu, M., Li, Z., Shi, Y., Zhang, X., Jiang, S. 2015. Evolution of regional inequality in the global shipping network. Journal of Transport Geography 44, 1-12. 